\title{
Characterisation and Index Properties Correlations for Marlstone and Marly Limestone of Saudi Arabia
}

\author{
Yassir M. Mustafa, Hamzah M. Al-Hashemi, Ahmed H. Bukhary \\ Department of Civil and Environmental Engineering, King Fahd University of Petroleum and Minerals \\ Dhahran 31261, Saudi Arabia \\ G201406420@kfupm.edu.sa; G201552950@kfupm.edu.sa; G201402400@kfupm.edu.sa
}

\begin{abstract}
It has been a common practice to estimate the Unconfined Compressive strength (UCS) of rock through correlations that relate it to other index parameters such as the Brazilian Tensile Strength (BTS) and the Ultrasonic Pulse Velocity $V_{p}$; nonetheless, selecting the most appropriate equation to use has always been a challenge considering the heterogeneity of rocks and their variant behaviour. Therefore, the use of equations which are especially developed for certain rock type at a specific location is recommended. This paper suggests 3 equations to predict UCS from BTS, bulk density $(\rho)$ and $V_{p}$ for marlstone of the Eastern Province of Saudi Arabia. 35 core samples are collected and tested in the laboratory for UCS, BTS and $V_{p}$. Statistical analysis is performed on the experimental results, and subsequently 3 statistical models that relate BTS, $V_{p}$, and rock bulk density $\rho$ to UCS are developed. Corrected correlation coefficients of the three models are found to be $0.575,0.663$, and 0.641 , respectively. Additional reliable equation that relate the bulk density to $V_{p}$ is produced with a corrected correlation coefficient of 0.95 .
\end{abstract}

Keywords: Unconfined Compressive Strength, Indirect Tensile Strength, Ultrasonic Pulse Velocity, Marlstone

\section{Introduction}

Unconfined Compressive Strength (UCS) is an indispensable parameter that has been commonly used in the analysis of geotechnical problems such as tunnelling, slope stability, and blasting. Determination of UCS through direct approach as standardised by the American Society for Testing and Materials [1], and International Society for Rock Mechanics [2] can be time-consuming, costly, and occasionally difficult to perform especially when adequate number of samples is not available, or when coring in weathered rock where proper samples cannot be extracted [3]-[6]. As a result, estimating UCS indirectly through correlations that relate index parameters like indirect tensile strength, ultrasonic pulse velocity, and rebound number (RN) of Schmidt Hammer became widely accepted due to the low cost, easiness, mobility, and short time associated with performing these tests. Quite a number of such correlations do exist in the literature; nevertheless, it is always difficult to make a decision on the most appropriate equation to use. Rocks are heterogeneous, and their behaviour varies from location to another; hence, one equation cannot be generalised. This study suggests three equations to estimate UCS from indirect tensile strength, bulk density and ultrasonic pulse velocity based on the experimental program conducted on marlstone and marly limestone samples obtained from the Eastern Province of Saudi Arabia.

\section{Previous Studies}

It is well-established that the BTS and other index parameters such as $V_{p}$ are related to UCS. Selcuk and Nar, 2016 [7] stated that predicting UCS from ultrasonic pulse velocity test only may not be accurate. They reported that different factors control the ultrasonic velocity, like discontinuities, moisture content, and micro cracks, which affect the reliability of the results. Therefore, the authors conducted both ultrasonic pulse velocity and Schmidt hammer tests on 42 samples of rocks including marlstone obtained from different locations in Turkey. Their statistical analysis yielded 4 equations. Karaman et al, 2015 [8] conducted a study on 47 rock samples from Black Sea region. The samples were tested for UCS, BTS and Triaxial compressive strength and an equation was created that relate indirect tensile strength to UCS. Azimian et al, 2013 [9] performed UCS, ultrasonic pulse and point load tests on 40 Marl rock samples obtained from Shiraz, Iran. They reported 8 different relationships between UCS and P-wave velocity. The authors compared their generated equations with 
previous studies, and found some differences due to the fact that marlstone was not sufficiently studied by researchers. In other words, their equations are applicable only to marlstones. They pointed out that ultrasonic velocity equations give good results for the velocities in the range 1145.67 to $3959.18 \mathrm{~m} / \mathrm{s}$. Further, very low or very high velocity may give poor estimation for UCS. Another study was conducted by Abdul-Jabbar, 2011 [10]. He evaluated the UCS, ultrasonic pulse velocity and point load index tests results of 57 rock samples obtained from Taq Taq dam, Iraq. The study yielded 2 equations that correlate the UCS with point load and ultrasonic pulse velocity. Table 1 summarises some of the recent studies.

Table 1: Summary of recent correlations between UCS and Vp, BTS, and RN.

\begin{tabular}{|c|c|c|c|c|}
\hline No & Rock type & Equation & R or $\mathbf{R}^{2}$ & Reference \\
\hline $\mathbf{1}$ & Igneous rocks & $\mathrm{UCS}=11.8-29.75 \mathrm{~V}_{\mathrm{p}}+7.11 \mathrm{~V}_{\mathrm{p}}^{2}$ & $\mathrm{R}=0.940$ & Selcuk and Nar [7] \\
& & & \\
\hline $\mathbf{2}$ & Marlstone & $\mathrm{UCS}=19.34 * \mathrm{Vp}^{1.21}-17.88$ & $\mathrm{R}^{2}=0.850$ & Shahri et al. [11] \\
\hline $\mathbf{3}$ & Different rock types & $\mathrm{UCS}=24.301+4.874 \mathrm{BTS}$ & $\mathrm{R}^{2}=0.900$ & Karaman et al. [8] \\
\hline $\mathbf{4}$ & Marlstone & $\mathrm{UCS}=0.026 * \mathrm{~V}_{\mathrm{p}}-20.207$ & $\mathrm{R}^{2}=0.909$ & Azimian et al. [9] \\
\cline { 3 - 4 } & & $\mathrm{UCS}=59.59 * \ln \left(\mathrm{V}_{\mathrm{p}}\right)-418.67$ & $\mathrm{R}^{2}=0.850$ & \\
\cline { 3 - 4 } & & $\mathrm{UCS}=0.0004 * \mathrm{~V}_{\mathrm{p}}^{1.4812}$ & $\mathrm{R}^{2}=0.902$ & \\
\cline { 3 - 4 } & & $\mathrm{UCS}=8.5078 * \mathrm{e}^{0.0006 \mathrm{~V}}$ & $\mathrm{R}^{2}=0.880$ & \\
\hline $\mathbf{5}$ & Marlstone & $\mathrm{UCS}=0.0353 \mathrm{~V}_{\mathrm{p}}-48.748$ & $\mathrm{R}^{2}=0.610$ & Hosseini et al. [12] \\
\hline $\mathbf{6}$ & Conglomerate & $\mathrm{UCS}=0.005 \mathrm{~V}_{\mathrm{p}}$ & $\mathrm{R}=0.940$ & Minaeian and Ahangari [13] \\
\hline $\mathbf{7}$ & Different rock types & $\mathrm{UCS}(\mathrm{MPa})=10.61 \mathrm{BTS}$ & $\mathrm{R}^{2}=0.500$ & Kahraman et al. [14] \\
\hline $\mathbf{8}$ & Different rock types & $\mathrm{UCS}=0.258 \mathrm{Vp}^{3.543}$ & $\mathrm{R}=0.920$ & Yagiz, [15] \\
\hline $\mathbf{9}$ & Different rock types & $\mathrm{UCS}(\mathrm{MPa})=5.364 \mathrm{~V}_{\mathrm{p}}$ & $\mathrm{R}^{2}=0.80$ & Abdul-Jabbar [10] \\
\hline $\mathbf{1 0}$ & Different rock types & $\mathrm{UCS}(\mathrm{MPa})=12.38 \mathrm{BTS}{ }^{1.0725}$ & $\mathrm{R}=0.890$ & Altindag and Guney [16] \\
\hline $\mathbf{1 1}$ & Sandstone, limestone & $\mathrm{UCS}=56.71 \mathrm{~V}_{\mathrm{p}}-192.93$ & $\mathrm{R}=0.810$ & Cobanglu and Celik [17] \\
& and cement mortar & & & \\
\hline
\end{tabular}

\section{Methodology}

\subsection{Sample Collection}

Marlstone and marly limestone rock types were selected for this study. Rock samples were collected from different locations within the Eastern Province of Saudi Arabia. A total of 43 rock cores were extracted. Extreme caution was exercised during sampling so as to obtain high-quality cores.

\subsection{Sample Preparation}

Rock cores were cut to the recommended test size in accordance with ASTM standards [18]-[20]. It is important to point out that Brazilian test was used to obtain the indirect tensile strength. Samples were carefully trimmed to ensure level surface while testing (Figure 1). cutting and trimming alongside

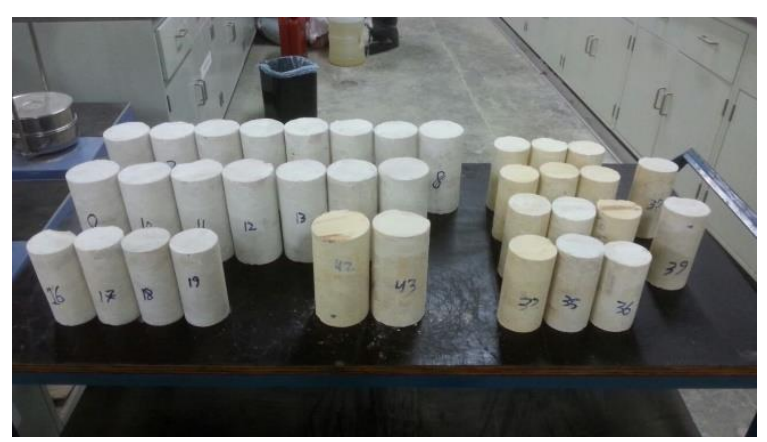

Rock cores that could not withstand those with noticeable 
Fig. 1: Prepared rock samples ready for testing.

flaws and fractures

were excluded. All rock

samples were oven-dried in preparation for conducting tests at zero moisture content.

\subsection{Experimental Work:}

Following the oven-drying of rock samples, ultrasonic pulse velocity was measured for all samples that yet to be tested for UCS. Moreover, the dry density was also determined for UCS and BTS samples. Afterwards, samples were tested for both UCS and BTS in accordance with ASTM standards [18]-[20]. At this stage, it was difficult to maintain a constant strain rate during the tests. Therefore, both tests were performed under specific stress rates as per ASTM standards [18][20]. For UCS test, a stress rate of $0.8 \mathrm{MPa}$ was maintained while a stress rate of $0.2 \mathrm{MPa}$ was sustained for the BTS test.

\subsection{Tests Results}

Results of the laboratory tests are summarised in Table 2.

Table 2: Summary of laboratory test results.

\begin{tabular}{|c|r|r|r|r|r|}
\hline \multirow{2}{*}{ No. } & \multicolumn{2}{|c|}{$\begin{array}{c}\text { Unconfined Compressive Strength and } \\
\text { Ultrasonic Pulse Velocity Tests }\end{array}$} & \multicolumn{2}{c|}{ Brazilian Test } \\
\cline { 2 - 6 } & $\rho\left(\mathrm{g} / \mathrm{cm}^{3}\right)$ & UCS $(M P a)$ & $V_{p}(\mathrm{~m} / \mathrm{s})$ & $\rho\left(\mathrm{g} / \mathrm{cm}^{3}\right)$ & $\mathrm{BTS}(\mathrm{MPa})$ \\
\hline $\mathbf{1}$ & 2.416 & 35.503 & 4043.956 & 2.348 & 1.913 \\
\hline $\mathbf{2}$ & 2.345 & 32.332 & 3655.556 & 2.268 & 4.094 \\
\hline $\mathbf{3}$ & 2.406 & 34.412 & 4063.830 & 2.400 & 2.578 \\
\hline $\mathbf{4}$ & 2.412 & 44.462 & 3882.353 & 2.374 & 2.205 \\
\hline $\mathbf{5}$ & 2.320 & 21.129 & 3391.304 & 2.406 & 2.478 \\
\hline $\mathbf{6}$ & 2.341 & 25.927 & 3413.870 & 2.390 & 3.136 \\
\hline $\mathbf{7}$ & 2.375 & 14.004 & 4182.320 & 2.285 & 0.671 \\
\hline $\mathbf{8}$ & 2.389 & 14.168 & 3776.808 & 2.395 & 2.807 \\
\hline $\mathbf{9}$ & 2.396 & 27.719 & 3854.061 & 2.155 & 0.432 \\
\hline $\mathbf{1 0}$ & 2.447 & 28.378 & 4293.103 & 2.223 & 2.729 \\
\hline $\mathbf{1 1}$ & 2.349 & 28.769 & 3386.062 & 2.208 & 1.571 \\
\hline $\mathbf{1 2}$ & 2.413 & 19.440 & 3923.077 & 2.239 & 1.575 \\
\hline $\mathbf{1 3}$ & 2.384 & 32.744 & 3735.000 & 2.491 & 1.573 \\
\hline $\mathbf{1 4}$ & 2.455 & 71.522 & 4102.981 & 2.432 & 1.680 \\
\hline $\mathbf{1 5}$ & 2.404 & 41.187 & 3882.353 & 2.295 & 0.664 \\
\hline
\end{tabular}

Table 2 (Cont'd): Summary of laboratory test results.

\begin{tabular}{|c|c|c|c|c|c|}
\hline \multirow{2}{*}{ No. } & \multicolumn{2}{|c|}{$\begin{array}{c}\text { Unconfined Compressive Strength and } \\
\text { Ultrasonic Pulse Velocity Tests }\end{array}$} & \multicolumn{2}{c|}{ Brazilian Test } \\
\cline { 2 - 6 } & $\rho\left(\mathrm{g} / \mathrm{cm}^{3}\right)$ & $\begin{array}{c}\text { UCS } \\
(M P a)\end{array}$ & $V_{p}(\mathrm{~m} / \mathrm{s})$ & $\rho\left(\mathrm{g} / \mathrm{cm}^{3}\right)$ & $\begin{array}{c}\text { BTS } \\
(M P a)\end{array}$ \\
\hline $\mathbf{1 6}$ & 2.275 & 19.626 & 3283.505 & 2.098 & 1.684 \\
\hline $\mathbf{1 7}$ & 2.202 & 6.363 & 3072.619 & 2.551 & 3.154 \\
\hline $\mathbf{1 8}$ & 2.426 & 20.017 & 3938.080 & 2.547 & 3.639 \\
\hline $\mathbf{1 9}$ & 2.467 & 22.015 & 4341.297 & 2.411 & 2.293 \\
\hline $\mathbf{2 0}$ & 1.614 & 5.128 & 1757.997 & 1.643 & 0.832 \\
\hline $\mathbf{2 1}$ & 1.493 & 4.531 & 2038.710 & 1.631 & 1.557 \\
\hline $\mathbf{2 2}$ & 1.718 & 8.299 & 1944.357 & 1.764 & 1.098 \\
\hline $\mathbf{2 3}$ & 1.712 & 6.919 & 1939.778 & 1.464 & 0.752 \\
\hline $\mathbf{2 4}$ & 1.655 & 2.142 & 1785.814 & 1.708 & 1.448 \\
\hline
\end{tabular}




\begin{tabular}{|l|l|l|l|l|l|}
\hline $\mathbf{2 5}$ & 1.666 & 5.849 & 1510.155 & 1.724 & 1.361 \\
\hline $\mathbf{2 6}$ & 1.645 & 5.478 & 1794.721 & 1.596 & 0.961 \\
\hline $\mathbf{2 7}$ & 1.575 & 3.892 & 1129.812 & 1.472 & 0.703 \\
\hline $\mathbf{2 8}$ & 1.609 & 3.810 & 1307.930 & 1.575 & 0.896 \\
\hline $\mathbf{2 9}$ & 1.686 & 6.240 & 1731.259 & 1.788 & 0.852 \\
\hline $\mathbf{3 0}$ & 2.040 & 1.668 & 2566.735 & 2.130 & 0.785 \\
\hline $\mathbf{3 1}$ & 1.832 & 4.860 & 1852.459 & 1.743 & 0.446 \\
\hline $\mathbf{3 2}$ & 1.871 & 5.210 & 1915.408 & 1.966 & 0.752 \\
\hline $\mathbf{3 3}$ & 1.907 & 5.498 & 1894.891 & 1.868 & 0.339 \\
\hline $\mathbf{3 4}$ & 1.859 & 15.280 & 2389.610 & 1.890 & 1.660 \\
\hline $\mathbf{3 5}$ & 1.966 & 7.908 & 1479.561 & 1.907 & 0.302 \\
\hline
\end{tabular}

\subsection{Statistical Analysis and Discussion}

As can be seen in Table 2 above, UCS value of the tested marlstone samples ranges between 1.67 and $71.52 \mathrm{MPa}$, BTS between 0.3 and $4.09 \mathrm{MPa}$, while $\mathrm{V}_{\mathrm{p}}$ ranges from 1129.81 to $4341.3 \mathrm{~m} / \mathrm{s}$.

Statistical analysis is performed on the data obtained from the laboratory experiments using SPSS Statistics v.23. Four prediction models are produced to correlate the UCS and pulse velocity with different parameters as shown in Table 3 . The level of significance for all models is 0.05 . In other words, the level of confidence is $95 \%$. The type of model is chosen so that best-fit prediction based on the correlation coefficient value is yielded. Magnitudes of the correlation coefficients can be interpreted as displayed in Table 4 [21].

Table 3: Prediction Models.

\begin{tabular}{|c|l|c|l|}
\hline No & \multicolumn{1}{|c|}{ Model } & $\begin{array}{c}\text { Adjusted } \\
\text { Correlation } \\
\text { Coefficient } \\
\left(\mathbf{R}^{2}\right)\end{array}$ & \multicolumn{1}{c|}{$\begin{array}{c}\text { Type of } \\
\text { Model }\end{array}$} \\
\hline 1 & $\mathrm{UCS}=0.299 \times e^{(1.8823 \times \rho)}$ & 0.641 & Exponential \\
\hline 2 & $\mathrm{UCS}=\ln \left(2.5644 \times e^{\left(0.005 \times \mathrm{V}_{\mathrm{p}}\right)}\right)$ & 0.663 & Exponential \\
\hline 3 & $\mathrm{UCS}=\mathrm{BTS}{ }^{-0.01}+\mathrm{V}_{\mathrm{p}}{ }^{0.511}-38.319$ & 0.575 & Linear \\
\hline 4 & $\mathrm{~V}_{\mathrm{p}}=3468.353 \rho^{2}-11085.754 \rho+10529.713$ & 0.950 & Quadratic \\
\hline Notes & \multicolumn{2}{|l|}{ Units: $\mathrm{UCS}$ is in $\mathrm{MPa}, \rho$ is in $\mathrm{g} / \mathrm{cm}^{3}, \mathrm{~V}_{\mathrm{p}}$ is in $\mathrm{m} / \mathrm{s}, \mathrm{BTS}$ is in $\mathrm{MPa}$} & \\
\hline
\end{tabular}

Table 4: Interpretation of correlation coefficient value [21].

\begin{tabular}{|l|l|}
\hline $\begin{array}{l}\text { Correlation } \\
\text { Coefficient }\end{array}$ & Interpretation \\
\hline $0.90-1.0$ & Very high correlation \\
\hline 0.70 to $<0.90$ & High correlation \\
\hline 0.50 to $<0.70$ & Moderate correlation \\
\hline 0.30 to $<0.50$ & Low correlation \\
\hline 0.00 to $<0.30$ & Negligible correlation \\
\hline
\end{tabular}

As shown in Tables 3 and 4, the correlation coefficients range from 0.575 to 0.950 which yields moderate to very high correlations. The moderate correlation level of models (1,2, and 3) can be attributed to the heterogeneity of these particular rock types which affects the UCS values markedly. Equation 4 proofs that bulk density is well-related to ultrasonic pulse velocity; the higher the density, the higher the pulse velocity. Correlation coefficient $\mathrm{R}^{2}$ value for equations (1) and (2) (0.641 and 0.663 , respectively) are close to those reported by Hosseini et al. [12], while other researchers like Ghazviniyan et al. and Kahraman [4], [22] reported even lower values. It should be pointed out that all of these studies were conducted on marlstone. Figure 2 illustrates the reliability of suggested correlation in comparison with previous studies. 


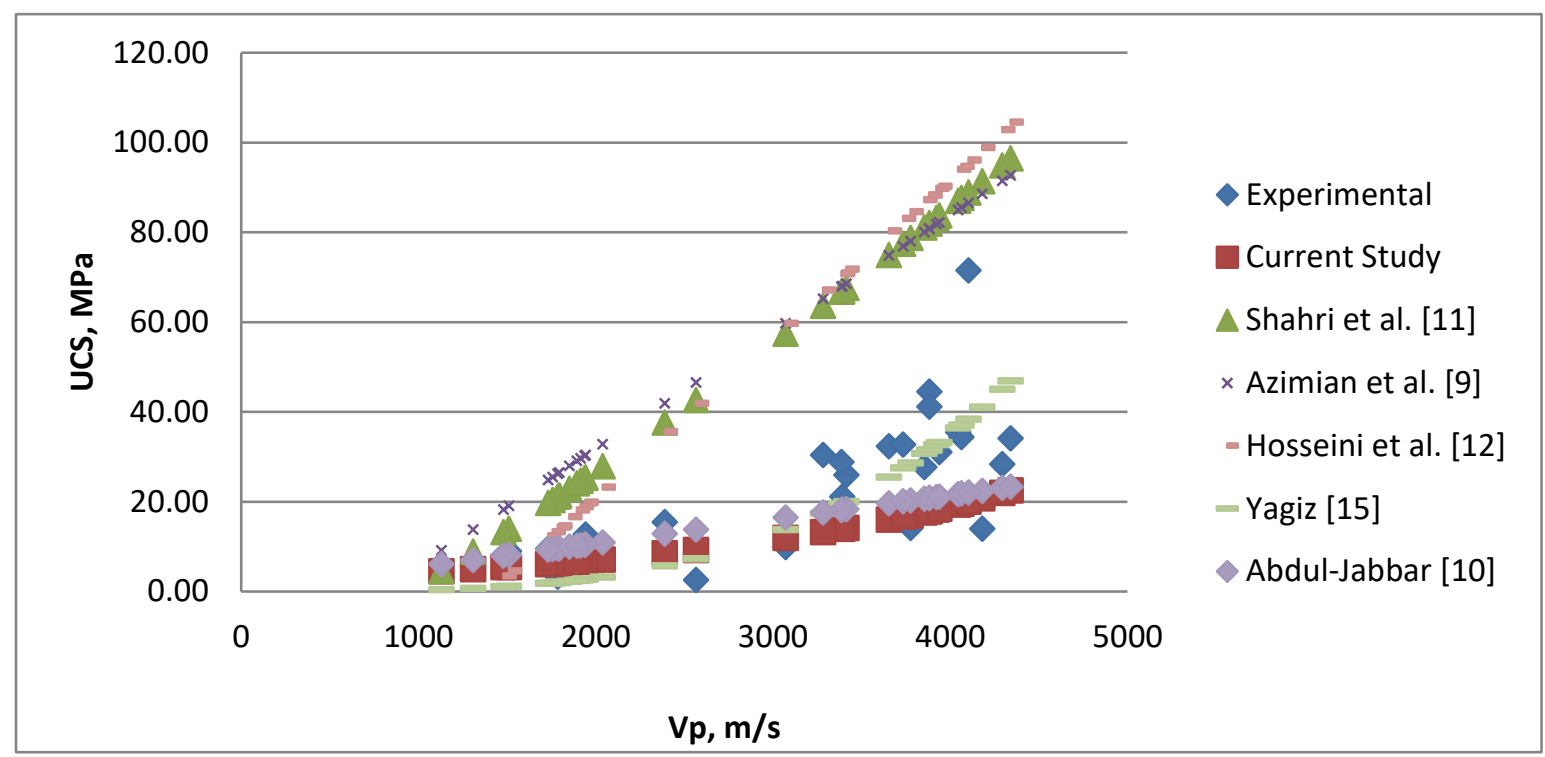

Fig. 2: Reliability of suggested correlation compared to previous similar studies.

\section{Conclusion}

A total number of 35 marlstone and marly limestone core samples collected from a different locations within Eastern Province of Saudi Arabia were tested for unconfined compressive strength, Brazilian tensile strength, and ultrasonic pulse velocity. Statistical analysis was performed on the test results, and subsequently, three equations with an acceptable degree of accuracy were generated for estimation of UCS from bulk density, ultrasonic pulse velocity, and both Brazilian tensile strength and ultrasonic pulse velocity, respectively. Correlation coefficients $\mathrm{R}^{2}$ of the three equations were found to be $0.641,0.663$, and 0.575 , respectively. An additional equation for prediction of ultrasonic pulse velocity from bulk density with high reliability and degree of accuracy $\left(\mathrm{R}^{2}=0.95\right)$ was also produced. Generally, suggested UCS equations are in good agreement with other studies conducted on marlstone.

\section{Acknowledgements}

The Authors would like to acknowledge the support of King Fahd University of Petroleum and Minerals. The authors are also grateful to Arab Centre for Engineering Studies (ACES) for providing test samples.

\section{References}

[1] Standard Test Method for Unconfined Compressive Strength of Intact Rock Core Specimens, Soil and Rock, Building Stones, Annual Book of ASTM Standards 4.08., ASTM, Philadelphia, Pennsylvania, 1984.

[2] Rock Characterization Testing and Monitoring, International Society for Rock Mechanics Suggested Methods, Ed. E. T. Brown Pergamon Press, Oxford, 1981.

[3] M. Romana, "Correlation between Unconfined Compressive and Point-Load (Miller tests) Strengths for Different Rock Classes," in 9th ISRM Congress, Balkema, Paris, pp. 673-676, 1999.

[4] S. Kahraman, "Evaluation of Simple Methods for Assessing the Uniaxial Compressive Strength of Rock," Int J Rock MechMin Sci, vol. 38, pp. 981-994, 2001.

[5] N. Ceryan, U. Okkan, and A. Kesimal, "Prediction of Unconfined Compressive Strength of Carbonate Rocks using Artificial Neural Networks," in Env. Earth Sci, 2012.

[6] R. Nazir, E. Momeni, D. J. Armaghani, and M. F. M. Amin, "Correlation between unconfined compressive strength and indirect tensile strength of limestone rock samples," in Electron. J. Geotech. Eng., vol. 18 I, pp. 1737-1746, 2013.

[7] L. Selçuk and A. Nar, "Prediction of uniaxial compressive strength of intact rocks using ultrasonic pulse velocity and rebound-hammer number," Q. J. Eng. Geol. Hydrogeol., vol. 49, no. 1, pp. 67-75, 2016.

[8] K. Karaman, F. Cihangir, B. Ercikdi, A. Kesimal, and S. Demirel, "Utilization of the Brazilian test for estimating the Uniaxial compressive strength and shear strength parameters," in J. South. African Inst. Min. Metall., vol. 115, no. 3, pp. 185-192, 2015. 
[9] A. Azimian, R. Ajalloeian, and L. Fatehi, "An Empirical Correlation of Uniaxial Compressive Strength with Pwave Velocity and Point Load Strength Index on Marly Rocks Using Statistical Method," Geotech. Geol. Eng., vol. 32, no. 1, pp. 205-214, 2014.

[10] M. A. Jabbar, "Correlations of point load in dexand pulse velocity with the uniaxial compressive strength for rocks," vol. 17, no. 4, 2011.

[11] A. Abbaszadeh Shahri, S. Larsson, and F. Johansson, "Updated relations for the uniaxial compressive strength of marlstones based on P-wave velocity and point load index test," Innov. Infrastruct. Solut., vol. 1, no. 1, p. 17, 2016.

[12] M. Hosseini, B. Alipanahi, and S. Senemari, "Determination of Engineering Properties of Marlstones Using Puch Test," Appl Geol, vol. 8, no. 4, pp. 309-322, 2013.

[13] B. Minaeian and K. Ahangari, "Estimation of Uniaxial Compressive Strength Based on P-wave and Schmidt Hammer Rebound Using Statistical Method," Arab J Geosci, vol. 67, pp. 491-498, 2013.

[14] S. Kahraman, M. Fener, and E. Kozman, "Predicting the Compressive and Tensile Strength of Rocks from Indentation Hardness Index," J. South. African Inst. Min. Metall., vol. 112, no. 5, pp. 331-339, 2012.

[15] S. Yagiz, "P-wave velocity test for assessment of geotechnical properties of some rock materials," Bull Mater Sci, vol. 34, no. 4, pp. 947-953, 2011.

[16] R. Altindag and A. Guney, "Predicting the Relationships between Brittleness and Mechanical Properties (UCS, TS and SH) of Rocks," Sci. Res. Essays, vol. 5, no. 16, pp. 2107-2118, 2010.

[17] I. Cobanglu and S. Celik, "Estimation of uniaxial compressive strength from point load strength, Schmidt hardness and P-wave velocity," Bull Eng Geol Env., vol. 67, pp. 491-498, 2008.

[18] ASTM, "Standard Test Method for Unconfined Compressive Strength of Intact Rock Core Specimens," D2938-95, 2002.

[19] ASTM, "Standard test method for splitting tensile strength of intact rock core specimens," D3967-08, 2008.

[20] ASTM, "Standard Test Method for Laboratory Determination of Pulse Velocities and Ultrasonic Elastic Constants of Rock," 2005.

[21] D. Agunbiade, Adebayo, and P. Ogunyinka, "Effect of Correlation Level on the Use of Auxiliary Variable in Double Sampling for Regression Estimation," Open J. Stat., p. 312, 2013.

[22] A. Ghazviniyan, A. Fathi, M. Rashidi, and M. Gharacheh, "Application of nondestructive tests in measurements of some physical and mechanical parameters of Zagros marls," in Mining Engineering Conference, Iran, 2005. 